\title{
La biopolítica de la deuda: relación acreedor-deudor
}

\author{
The biopolitics of debt: creditor-debtor \\ relationship
}

\section{A biopolítica da dívida: relação credor- devedor}

Fecha de recepción: 9 de mayo de 2017

Fecha de evaluación: 25 de julio de 2017

Fecha de aceptación: 31 de octubre de 2017

Disponible en línea: 21 de noviembre de 2017

Jorge Eliécer Martínez Posada*

Lina María Vivirescas Molina**

Catalina Puentes Rodríguez ${ }^{* * *}$

DOI: https://doi.org/10.18359/rlbi.2872

\author{
Cómo citar: \\ Martínez Posada, J. E., Vivirescas Molina, L. M. y \\ Puentes Rodríguez, C. (2018). La biopolítica de la \\ deuda: relación acreedor-deudor. Revista Latinoa- \\ mericana de Bioética, 18(1), 87-103. \\ Doi: https://doi.org/10.18359/rlbi.2872
}

* $\quad$ Posdoctor en Filosofía, Universidad de Cádiz y en Ciencias Sociales, Centro Internacional de Educación y Desarrollo Humano (CINDE)-Consejo latinoamericano de Ciencias Sociales (Clacso); doctor en Filosofía, programa Historia de la Subjetividad, Universidad de Barcelona; doctor en Ciencias Sociales Niñez y Juventud, Centro Internacional de Educación y Desarrollo Humano (CINDE)-Univeridad de Manizales; diploma de Estudios Avanzados (DEA) en Filosofía, Universidad de Barcelona; magíster en Desarrollo Educativo y Social, (CINDE), Universidad Pedagogica Nacional; licenciado en Filosofía,Universidd de San Buenaventura. Miembro del grupo Intersubjetividad en la Educación Superior y del grupo Subjetivaciones, Ciudadanías Críticas y Transformaciones Sociales, de Clacso. Catedrático de la pontificia Universidad Javeriana, miembro de la red Internacional de Investigadores en Subjetividades Políticas, director de la línea de Socialización y Subjetividades Políticas CINDE-UPN y profesor titular III de la Universidad de La Salle, Bogotá, Colombia. Correo electrónico: jormartinez@unisalle.edu.co. ORCID: https://orcid.org/0000-0003-4377-6872

** Magíster en Educación, licenciada en Pedagogía Infantil y diplomada en Evaluación y Planeación Educativa, Pontificia Universidad Javeriana. Docente de la Facultad de Educación de la Pontificia Universidad Javeriana, Bogotá, Colombia. Correo electrónico: lvirviescas@javeriana.edu.co. ORCID: https://orcid.org/0000-0002-7345-886X

*** Magíster en Educación, Pontificia Universidad Javeriana; especialista en Gerencia Social, Corporación Universitaria Minuto de Dios; licenciada en Psicología y Pedagogía, Universidad Pedagógica Nacional. Secretaria Académica de la Facultad de Ciencias Humanas y Sociales, Corporación Universitaria Minuto de Dios, Bogotá, Colombia. Correo electrónico: capuentes@uniminuto.edu ORCID: https://orcid.org/0000-0002-2084-2032. 

la figura del crédito o la deuda en el campo de la educación superior, a partir de una lectura histórica de la deuda y la relación acreedor-deudor en su interior, planteada esta como una relación de poder.

Desde la comprensión de la deuda como un dispositivo de control biopolítico constitutivo del aparato neoliberal, esta se traslada al campo de la educación a través de la figura de crédito educativo, que está disponible a toda la población y facilita el acceso a la educación superior, y alimenta así un ideal de inversión a largo plazo con la promesa infinita de la conquista de un sujeto "empresario de sí mismo", que se encuentra en una procura permanente de recursos que le permitan mantener la inversión en sí mismo como aparato productivo.

Así, este análisis consigue plantear el ideal del sujeto aparentemente independiente, que se sumerge en la deuda como mecanismo de acceso a los recursos que le acercan a la meta de ser "su propio jefe", como la esencia de uno de los engranajes principales en los modos de sujeción de la conducta, propios del neoliberalismo, y su mecanismo de la deuda, aplicados al campo de la educación. Sobre esta base tiene lugar una "pedagogía de la deuda" en la cual emergen como elementos indispensables en la fabricación de dicho sujeto la universidad y la educación superior.

Palabras claves: biopolítica, acreedor-deudor, pedagogía de la deuda, subjetividad.

\section{Abstract}

This article proposes an analysis of the biopolitical devices that are behind the figure of credit or debt in the higher education field, based on a historical reading of the debt and the creditor-debtor relationship, explained as a relationship of power.

From the understanding of the debt as a biopolitical constitutive device of control of the neoliberal apparatus, it is transferred to the field of education through the figure of educational credit, which is available to the entire population and facilitates access to higher education. And thus feeds an idea of long-term investment with the infinite promise of the conquest of a subject "entrepreneur of himself," who finds himself in a permanent pursuit of resources that allow him to maintain the investment in himself as a productive apparatus.

Therefore, this analysis manages to pose the idea of the apparently independent subject, who immerses himself in the debt as a mechanism of access to resources that bring him closer to the goal of being "his own boss", as the essence of one of the main gears in modes of subjection of behavior, typical of neoliberalism, and its mechanism of debt, applied to the field of education. On this basis, there is a "debt pedagogy" in which the university and higher education emerge as indispensable elements in the manufacture of said subject.

Keywords: biopolitics, creditor-debtor, debt pedagogy, subjectivity

\section{Resumo}

O presente artigo propõe uma análise dos dispositivos biopolíticos que estão por trás da figura do crédito ou a dívida no campo do ensino superior, desde em uma leitura histórica da dívida e do relacionamento credor-devedor dentro dela, levantada ela como uma relação de poder.

Desde a compreensão da dívida como um dispositivo de controle biopolítico constitutivo do aparelho neoliberal, esta é transferida para o campo da educação através da figura do crédito educacional, que está disponível para toda a população e facilita o acesso ao ensino superior, e assim alimenta um ideal de investimento em longo prazo com a infinita promessa da conquista de um sujeito "empresário de si mesmo", que se encontra em uma busca permanente de recursos que lhe permitam manter o investimento em si mesmo como um aparelho produtivo.

Assim, esta análise consegue levantar o ideal do sujeito aparentemente independente, que se submerge na dívida como um mecanismo de acesso aos recursos que o aproximam ao objetivo de ser "seu próprio chefe", como a essência de uma das engrenagens principais nos modos de sujeição do comportamento, próprio do neoliberalismo, e seu mecanismo da dívida, aplicados ao campo da educação. Nesta base, tem lugar uma "pedagogia da dívida" na qual emergem como elementos indispensáveis na fabricação do referido sujeito à universidade e o ensino superior.

Palavras-chave: biopolítica, credor-devedor, pedagogia da dívida, subjetividade. 


\section{Introducción}

La sociedad actual está inmersa en la economía de la deuda que, en palabras de Lazzarato (2013), es entendida como una promesa de reembolso en un futuro más o menos lejano, pero siempre imprevisible. "El crédito o deuda y su relación acreedor-deudor constituyen una relación de poder específica que implica modalidades específicas de producción y control de la subjetividad (una forma particular de homo oeconomicus, el ?hombre endeudado?)" (p. 36). Es decir, se trata de una biopolítica de la gestión de la fuerza productiva, cuestión que Michel Foucault, a través del concepto de biopolítica, nos había anunciado desde los años 70 y lo que hoy en día va haciéndose evidente: la "vida" y lo "viviente", que son los retos de las nuevas luchas políticas y de las nuevas estrategias económicas.

Los préstamos universitarios se han convertido para los jóvenes que quieran acceder a una formación profesional en la nueva forma de financiación de sus carreras, pues al realizar una mirada detenida en relación con la educación superior podemos encontrar que esta se ha convertido en un beneficio para quienes tienen condiciones económicas privilegiadas; por el contrario, otros jóvenes y sus familias deben conformarse con adquirir grandes deudas para de tener un "mejor futuro". Este panorama nos enseña que germina un asentamiento a la desigualdad y el desequilibrio en el acceso a la educación superior, donde se posiciona una educación que dejó de ser un beneficio social para convertirse en un lujo particular. Por tanto, los créditos universitarios se han configurado como la principal fuente de financiación de los estudios profesionales, siendo el endeudamiento la nueva realidad en la vida de los jóvenes. "La llamada ?financiación? constituye no tanto una modalidad de finan- ciamiento de las inversiones, sino un enorme dispositivo de gestión de la deudas privadas y públicas y, por ende, de la relación acreedor-deudor, gracias a las técnicas de titulización" (Lazzarato, 2013, p.p 28 y 29).

Ahora bien, la pedagogía de la deuda se convierte en la forma de nombrar a la deuda constante en la cual se registran los jóvenes, con la finalidad de obtener el servicio de educación superior que ha dejado de ser un derecho y resulta cada vez más privatizado. "Esta deuda llega a convertirse en un "paradigma" y resulta decisiva, pues su monto ha aumentado considerablemente para cuando el joven se gradúa" (Martínez, 2014, p. 103). En ese sentido, el aspecto fundamental que se destaca aquí es el paso de la educación superior como bien social a un bien individual. En este giro, los individuos "atomizados" ingresan a la educación superior en busca de un mejor trabajo o mayores ingresos, y en este punto la lógica del mercado funciona como un plus para el potencial económico y "los préstamos son una inversión personal, no social; por ello, su horizonte se proyecta hacia la potencia del individuo, y no de la sociedad en su totalidad" (Martínez, 2014, p. 104).

Los procesos económicos devienen entonces espacios para la producción de la subjetividad en una "producción de productores" y no se organiza solamente desde dispositivo de corte disciplinario, sino también desde una captura y un diseño biopolítico de la subjetividad. En el sentido de este término, la producción de subjetividad desde las técnicas gubernamentales del liberalismo supone entonces la emergencia de una forma vital productiva que está regulada por las leyes del mercado y que además se convierte en un modelo social codificado por la "empresa", siendo la deuda una inversión en la propia subjetividad en términos de ser o proyec- 
tarse sujeto empleable. Estas son "características de la cuestión del "sujeto competente y competitivo" y de la educación como una herramienta constante en la producción y el mantenimiento de la subjetividad" (Martínez, 2014, p. 107).

\section{El crédito o la deuda: relación acreedor y deudor}

La deuda, vista desde una postura positiva, no es más que una de las amplias ventajas para el desarrollo y crecimiento, así como una de las principales fuentes del motor económico y subjetivo de la economía contemporánea. La fabricación de deuda como configuración y desarrollo de las relaciones de poder entre acreedor y deudor se ha diseñado y programado como la célula estratégica de las políticas neoliberales, dado que:

\begin{abstract}
La deuda actúa a la vez como máquina de captura, de depredación o de punción sobre la sociedad en su conjunto, como un instrumento de prescripción y gestión macroeconómica y como un dispositivo de redestribución de los ingresos. Funciona asimismo, en cuanto dispositivo de producción y gobierno de las subjetividades colectivas e individuales. (Lazzarato, 2013b, p. 35)
\end{abstract}

Dentro de esta noción, cabe anotar que se han venido configurando nuevas formas y funciones de las finanzas, puesto que se puede apreciar la capacidad de transformar el dinero en deuda y la deuda en propiedad, lo que influye directamente sobre las relaciones sociales que estructuran la esfera social. Sin embargo, la relación acreedor y deudor no solo está concentrada específicamente en influir sobre las relaciones sociales, sino que es de por sí una relación de poder: la más universal del capitalismo contemporáneo.
El crédito o la deuda y su respectiva relación acreedor- deudor constituyen entonces una relación específica de poder que implica propiedades concretas de corte productivo y de control de la subjetividad, lo cual produce una forma de subjetividad particular, la del "hombre endeudado". Si bien "La relación acreedor-deudor se supone en las relaciones capital-trabajo, Estado benefactor-usuario y empresa-consumidor y las atraviesa, instruyendo como 'deudores' a usuarios, trabajadores y consumidores" (Lazzarato, 2013b, p. 36), esta relación de poder se sostiene "libre" a aquel sobre el cual se ejerce el poder que comprende la deuda y modula un ejercicio de libertad, pero a la vez incita a actuar para poder cancelar la respectiva deuda. Si bien el neoliberalismo gobierna por medio de un conjunto amplio de relaciones de poder inscritas previamente, la relación acreedor-deudor involucra a la población actual en su conjunto, sin desligar a las futuras.

Los economistas aseguran que cada bebé francés tiene al nacer una deuda de 22.000 euros. Podemos decir así que ya no se trata del pecado original que se nos transmite con el nacimiento, sino la deuda de las generaciones precedentes que recae en los nuevos nacidos. En ese sentido, Lazzarato (2013b) nos ilustra indicando que:

$$
\begin{aligned}
& \text { El "hombre endeudado" está sometido a } \\
& \text { una relación de poder acreedor-deudor } \\
& \text { que lo acompaña a lo largo de toda la vida, } \\
& \text { desde la cuna hasta la tumba. Si antaño } \\
& \text { nos endeudábamos con la comunidad, con } \\
& \text { los dioses, con los ancestros, ahora estamos } \\
& \text { en deuda con el "dios" Capital. (p. 39) }
\end{aligned}
$$

Esto nos permite pensar la deuda como dispositivo de poder en el paradigma de la relación social, en dos escenarios consecuentes. 
En primer lugar, la deuda hace que la sociedad, como su respectiva economía, inicie por una asimetría de poder, más no por el intercambio comercial que enlaza la igualdad; demarcar puntos diferenciales de poder en el contexto de los grupos sociales e involucrar una nueva definición de la moneda, porque de entrada ella se manifiesta como patrón de mando, poder de destrucción como de creación sobre lo concerniente al campo de lo económico y lo social. En segundo lugar, iniciar por la deuda implica que la economía sea inminentemente subjetiva, ya que es "una relación económica que para realizarse presupone una modelización y un control de la subjetividad, de tal manera que el ?trabajo? sea indisociable de un "trabajo sobre sí mismo" (Lazzarato, 2013, p. 41).

En ese sentido, Deleuze y Guattari (1972) desarrollan una interesante lectura respecto a la teoría marxista, en la cual su primer foco se concentra en la relación entre acreedor-deudor y el segundo foco obedece a la univocidad del concepto de producción respecto a la producción de subjetividad, modalidades y formas de vida, sin aludir a la macroestructura; por el contrario, haciendo parte de la infraestructura "económica". Esto quiere decir que en la economía contemporánea, la subjetividad producida implica un rasgo importante que permite demostrar que se constituye como la naciente, primera y esencial fuente de producción y mercancía, que interviene y deviene en la producción de todas las demás.

\section{Deleuze y Guattari una lectura de la deuda}

Para este apartado partiremos de la lectura que Deleuze y Guattari (1972) elaboran respecto a la deuda, en un desarrollo corte histórico, a fin de acentuar la claridad y agudeza que conjuga la lógica en la economía contemporánea en su amplia obra El anti-Edipo: capitalismo y esquizofrenia, donde se conectan ideas de Nietzsche expresadas en La genealogía de la moral, con la teoría marxiana del dinero. Las nociones que Deleuze y Guattari enuncian implican coordenadas conceptuales de la economía como aspectos indisociables de la producción, el control y las formas de existencia de la subjetividad. Así, el capital es poder de mando y disposición (en sentido foucaultiano), que se ejerce por medio de la capacidad de creación, destrucción y distribución de moneda: un dispositivo que, más allá de su función como mecanismo de pago, es un elemento de atesoramiento, lo que sería en síntesis una expresión de poder.

Siguiendo a Nietzsche (1873), los autores indican que las relaciones sociales no se sostienen en un contrato entre las partes que la componen, sino que se configuran con respecto a los diferenciales de poder en una amplia variabilidad de potencialidades. No se comprende la uniformidad del intercambio de orden económico sobre la que puede constituirse, dado que estas funcionan por medio de una lógica que no es de igualdad y correspondencia, sino de violencia y usurpación, lo que explica la asimetría deuda/crédito que antecede histórica y teóricamente a las lógicas de la dinámica de producción y al trabajo asalariado. En ese sentido Deleuze y Guattari (1972) indican que:

Hay un desequilibrio fundamental a nivel de cada flujo, sea cual sea su calificación, en la relación de intercambio. Esto quiere decir que no hay intercambio, que hay un sistema de deuda, y que la deuda está afectada fundamentalmente por un desequilibrio funcional [...]. (p. 190) 
El desequilibrio (entre la dinámica de dar y de recibir) es fundamental y permanente; por consiguiente, no se está ante una consecuencia anómala, sino ante un aspecto que es parte cardinal del sistema social. Frente a esto, se puede pensar que a partir de la articulación entre la teoría nietzscheana del crédito en las sociedades arcaicas y la teoría marxista de la moneda en el capitalismo, los autores esbozan un breve mapa histórico de la deuda, que se enmarca en una presentación no economista de la economía, donde su fundamento no se concentra en el intercambio, sino en una relación de poder asimétrico entre acreedor y deudor. Una lectura no economicista de la economía significa, por un lado, que la producción económica es indisociable de la producción y el control de la subjetividad y sus formas de existencias; por el otro, que la moneda, antes de cumplir las funciones económicas de medida, medio de intercambio, pago o atesoramiento, es expresión de un poder de mando y distribución de lugares y tareas de los gobernados (Lazzarato, 2013, p. 83).

La simetría que se instaura en el crédito de la economía de la deuda sienta las líneas de una concepción de moneda, en la cual funciones políticas y económicas son indistinguibles, lo que implica que al revisar el concepto de poder enunciado por Foucault (1999) se comprende que en relación con la moneda, precisamente "el capital es, en primer lugar, un orden de mando y prescripción que se ejerce a través de la capacidad de destrucción y creación de la moneda" (Lazzarato, 2013b, p. 84).

En este orden, Deleuze nos permite iluminar con precisión una crítica que se focaliza en la marcación diferencial del poder, el capital y la moneda, y pone de manifiesto cómo se entraman en un sistema complejo difícil de percibir para un observador puramente economista. El capitalismo disimula objetivamente el hecho de que la moneda funciona de dos modos distintos: como ingreso y como capital. En el primero, la moneda es un medio de pago (salario e ingreso) que compra una cantidad de bienes ya existentes y constituidos en la producción capitalista, y se limita a reproducir las relaciones de poder y las modalidades de sujeción establecidas y necesarias para dicha producción. En el segundo, la moneda funciona como estructura de financiamiento (moneda de crédito y cuasi moneda de las finanzas), es decir que tiene la posibilidad de escoger y decidir en lo atinente a las producciones y mercancías futuras, y, por lo tanto, a las relaciones de poder y las obligaciones que las sostienen. "La moneda como capital se arroga un derecho preferencial sobre el futuro" (Lazzarato, 2013a, p. 85).

Considerado así, por un lado, la moneda-ingreso es una noción clara de reproducción de las relaciones de poder, segmentación del trabajo y asignación de funciones y roles instaurados; por otro lado, vista como capital, tiene la capacidad de reconfigurarlas, cuestión que se constituye como noción legible con el neoliberalismo. Mientras que la moneda-deuda fue el arma estratégica de devastación del fordismo y de construcción en la creación de perfiles de un nuevo orden del sistema capitalista, un orden de corte mundial: "Las finanzas-deuda no son, una simple convención, una mera funcionalidad de la economía real. Representan al capital social y al "capitalismo colectivo", al "común" de la clase de los capitalistas" (Lazzarato, 2013b, p. 86). Al respecto, la postura de Deleuze (1968) vuelve a la teoría de Marx y la desata de ambigüedades como el impedimento de madurar un sistema económi- 
co mercantil en sí, ya que está vinculada a la economía monetaria y, por ende, a la economía de la deuda. Al sistema económico lo define una subordinación a ellas, y se quiebran así los poderes, dominaciones, obligaciones, se imposibilita el hecho de que la moneda proceda de la mercancía y a su vez se adiciona el trabajo. En efecto:

Los ordena, los gobierna, organiza su distribución. La asimetría de poder, los diferenciales de poder que se expresan en la moneda-deuda son válidos para cualquier sociedad: sociedad arcaica, sociedad antigua, sociedad feudal, capitalismo. Lo que atraviesa e informa a una sociedad nunca es un circuito de intercambio: es un circuito completamente diferente que no remite a la aritmética. No se trata de cantidades iguales o desiguales que entren en una relación de intercambio, sino de cantidades de potencia diferentes, cantidades de potencia en el sentido matemático de la palabra, potencialidades diferentes. (Lazzarato, 2013a, p. 86)

El intercambio nunca es primario, pues aunque las esferas económicas de las sociedades no funcionan bajo los canales del intercambio económico o simbólico, es claro precisar que para Lazzarato (2013b), las sociedades, en la configuración de su organización, se fundamenta sobre la base de discrepancias de poder en un desequilibrio de potencialidades. Esto teniendo en cuenta que el intercambio no existía en absoluto, sino que se consolida por medio de una lógica que no es la de igualdad sino la del desequilibrio, en la diferencia. Deleuze (citado en Lazzarato, 2013b, p. 90) añade que en las sociedades arcaicas:

No hay formas de intercambio, no hay formas de equivalencia [...]: hay un sistema de deuda y la deuda está fundamentalmente afectada por un desequilibrio funcional [...] Por ejemplo, el desequilibrio entre dar y recibir objetos de consumo está, digamos, funcionalmente no reequilibrado -el desequilibrio es fundamental y constante - sino desequilibrado; sólo funciona desequilibrado. (p. 87).

Este panorama expuesto sirve como preámbulo para iluminar unas aristas propias del marco histórico de la deuda en Deleuze y Guattari. Dichas aristas corresponden, en primer lugar, a la deuda infinita; en segundo lugar, a los movimientos bárbaros, y en tercer lugar, a los movimientos capitalistas. Para la primera línea o arista, la deuda infinita encierra:

El paso de la deuda finita a la deuda infinita, cuando se sale de las sociedades arcaicas, constituye un acontecimiento cuales consecuencias se hacen sentir aún en nuestros días, porque el capitalismo hizo suyo ese paso con visitas a la producción del hombre endeudado que no terminará jamás de reembolsar. En efecto: con grandes imperios que al centralizar y concentrar el poder en formas estatales signan el fin de las sociedades arcaicas, y con el advenimiento de las religiones monoteístas, que centralizan y concentrar el poder espiritual, la deuda ya no puede rescatarse: el sistema de combinaciones finitas y móviles de las sociedades arcaicas es sustituído por un régimen de la deuda infinita. (Lazzarato, 2013, p. 89)

En este orden de ideas, la deuda se ubica en la relación entre un deudor que no termina de pagar y un acreedor que no culminará de extenuar los intereses de la deuda:

[...] deuda con la divinidad, deuda con la sociedad, deuda con el Estado. Jugada genial 
del cristianismo, porque la Santísima Trinidad incluye en sí misma al acreedor y al deudor: Dios que se sacrifica para pagar la deuda del hombre, Dios que se hace pagar a sí mismo, Dios como único capaz de rescatar al hombre de aquello que el hombre se ha tornado incapaz de rescatar: el acreedor que se sacrifica por su deudor, por amor (¿alguien puede creerlo?). ¡Por amor a su deudor! (Deleuze (1971), citado por Lazzarato, 2013b, p. 89)

En las formas soberanas previas al cristianismo la deuda era evidentemente infinita pues, paralelo y en discrepancia con las sociedades arcaicas; su operatividad estatal hacía que no fuera posible reembolsarla, ni tampoco establecer un equilibrio en las distancias diferenciales de poder definidas por el intercambio siempre desigual. Al introducir el infinito en el cristianismo, se reconfigura en amplitud el régimen de la deuda y se establece una permanente renovación que adopta el capitalismo.

La especificidad del cristianismo consiste en que nos ha situado no solo bajo el régimen de la deuda, sino también bajo el régimen de la deuda interiorizada. El dolor del deudor se interioriza y la responsabilidad de la deuda se convierte en un sentimiento de culpa. (Lazzarato, 2013b, p. 90)

Como segunda arista, se encuentran los movimientos bárbaros, donde la economía mercantil no comprende una autonomía como tal y prescinde de un flujo de poder y una potencia de desterritorialización. Desde el perímetro del imperio, los vikingos con sus modos de instrumentalización y los barcos, y los húngaros con sus caballos como elementos de movilidad, flujos de migración y movimientos superiores a la movilidad campesina, se arrojaban sobre él y saqueaban viviendas (al- deas), monasterios y tumbas. Mientras que los flujos con "menor rango" (los campesinos) se subordinaron al movimiento nómada y móvil (los guerreros bárbaros).

Los flujos bárbaros son flujos desterritorializados, pero también desterritorializantes. Si el dinero, en su carácter de medio de pago, medida, etc., es un flujo desterritorializado, su fuerza desterritorializante no proviene de él mismo, sino de los flujos de poder destructores/creadores impulsados por los bárbaros (o, más adelante, por capitalistas o fuerzas revolucionarias). (Lazzarato, 2013b, p. 94)

Los signos monetarios estériles deben su potencia al movimiento nómada, móvil, migratorio, bárbaro. Con respecto a los bárbaros, los campesinos escapaban y en medio de esta huida se veían afectados por un coeficiente secundario de desterritorialización, que en medio de este escape podía obtener una potencia que no tenía como campesino inactivo. El poder de destrucción/creación no es un valor o propiedad del dinero como tal; este último debe comprender una profunda modificación en capital, es decir, en poder de destrucción/creación.

Como tercera línea, están los movimientos capitalistas. Al respecto, Deleuze y Guattari (1972) indica que jamás la economía (cualquiera que sea) operó como economía de corte mercantil. En una formación social, independientemente de la que fuese, una economía solo puede demarcar los intercambios y movilizar los circuitos que la determinan sobre la base de la moneda como poder adquisitivo, en función de otros flujos. El intercambio corresponde a una dimensión secundaria frente a algo de "otra naturaleza" (Deleuze y Guattari, 1972), otra naturaleza 
que obedece a un sentido muy riguroso y que configura un flujo de otra potencia.

En el capitalismo, el dinero es una expresión de flujo, de potencia heterogénea. El poder adquisitivo representa un conjunto de medios de pago (ingresos-salarios) que se realizan por la compra de bienes ya presentes, producidos dentro de una lógica estrictamente subordinada, siendo esta flujo de menor potencia. Ahora, respecto a los flujos de financiación, estos no representan un mero poder adquisitivo en reciprocidad dinero-bienes, sino que configuran un poder de cumplimiento, prescripción, ordenamiento, que vinculado al conjunto de posibilidades de elección y disposiciones que se ejercen sobre el futuro anticipan lo que va a ser la producción, las relaciones de poder y, por consiguiente, las modalidades de sujeción. Lazzarato (2013b), al respecto, indica lo siguiente:

El poder de la moneda como estructura de financiación no proviene de un poder adquisitivo más grande, y la fuerza de un capitalista no depende del hecho de ser más rico que un obrero. Su poder obedece a que maneja y determina la dirección del flujo de financiación, es decir que dispone del tiempo como decisión, como elección, como posibilidad de explotar, someter, mandar dirigir a otros hombres. La moneda como poder adquisitivo es, para Deleuze, el factor mediante el cual se reterritorializan y se fijan los flujos de trabajo en el consumo, la familia, el empleo y las obligaciones (obrero, profesor, hombre, mujer, etc.), que son otras tantas asignaciones de la división del trabajo. ( p. 96)

El flujo de financiación, entendiendo el dinero como capital, es un poder metamorfoseado que muta en un movimiento creado en un compendio de signos poderosos que comprometen el futuro, una fuerza de poder que constituye destrucción o creación, expresión de una fuerza de prescripción (cumplimiento) que predice lo que aún no está presente. En este orden de ideas, es relevante acentuar, desde los postulados de Deleuze y Guattari (1972), que la materia del dinero como capital es sin duda el elemento del tiempo, mas no específicamente del tiempo del trabajo, sino del tiempo en cuanto posibilidad de elección, decisión y poder; es decir, el poder de destrucción/creación de las modalidades y esferas de lo social de explotación y sujeción.

Por otro lado, el dinero ubicado como medio de pago es un signo estéril (impotente), dado que únicamente opera como vehículo para adquirir mercancías que ya están presentes, con lo que se establece:

Una relación biounívoca entre la moneda y un abanico impuesto de productos. El ser adquisitivo, "el dinero representa un corte -extracción posible sobre un flujo de consumo" dado (relaciones de poder dadas); en la estructura de financiación, funciona como "posibilidad de corte-separación" que articula cadenas de valoración y acumulación del capital, reconfigura la composición de la fuerza del trabajo y de la población, y bosqueja nuevas modalidades de sujeción. La especificidad del poder capitalista no deriva de una simple acumulación de poder adquisitivo, sino de la capacidad de reconfigurar las relaciones de poder y los procesos de subjetivació.n (Lazzarato, 2013b, p. 99)

Al proceder la moneda de la deuda y afinar su naturaleza infinita que se sintoniza a la producción para la producción, el dinero y 
su circulación, es camino para que la deuda adopte su carácter infinito.

[...] la abolición de las deudas o su transformación contable inaugura la tarea de un servicio estatal interminable [...]. El acreedor infinito, la creencia infinita, han reemplazado a los bloques de deudas móviles y finitas [...]. La deuda se convierte en deuda de existencia, deuda de existencia de los sujetos mismos. Llega el tiempo en que el acreedor todavía no ha prestado mientras el deudor no deja de devolver, porque devolver es un deber pero prestar es una facultad (Deleuze y Guattari, 1972 pp. 233 y 234).

La acción neoliberal por medio de la gestión de la deuda, descrita en El anti-Edipo: capitalismo y esquizofrenia, comprende la univocidad de la producción que transita y envuelve de manera nebulosa la economía y la subjetividad. La economía de la deuda es una economía que configura y determina un tipo de sujeto particular, un sujeto capaz de responder por sí mismo como futuro, de prometer y mantener dicha promesa, ejerciendo un trabajo empresarial sobre sí mismo.

\section{La deuda en el neoliberalismo}

La deuda es sin lugar a dudas uno de los dispositivos constituyentes en la relación de poder más desterritorializada, y el marco general a través del cual el aparato de poder neoliberal dispone una organización específica de lucha de clases. La deuda representa una relación de poder transversal que se ciega fronteras y Estado; las discrepancias entre lo económico, lo político y lo social, así como los dualismos de la producción descritos por Lazzarato (2013a) activo/no activo, empleo/ desempleado, productivo/no productivo ( $\mathrm{p}$.
103) responden a la actuación de orden mundial en el nivel inmediatamente planetario, e incita la germinación y fabricación "ética2 del hombre endeudado.

La economía de la deuda interviene de manera indistinta en zonas geopolíticas como vehículo de presión en la mayoría de los conflictos de orden social y al mismo tiempo ejerce su poder sobre los sujetos (endeudamiento de las familias), y de esta manera encarna el capitalista colectivo (Lazzarato, 2013a, p. 104). Este marco preliminarmente expuesto permite indicar que: "la metamorfosis del capitalismo y de su moneda, resume así el paso de la gobernanza disciplinaria al neoliberalismo contemporáneo: El hombre ya no es el hombre encerrado de sociedades disciplinarias, sino el hombre endeudado de sociedades de control" (Deleuze, citado en Lazzarato, 2013b, p. 92).

Para Foucault (2007), los neoliberales ya no conciben al homo œconomicus como el sujeto del intercambio y el mercado, sino como un sujeto atado a la noción de un empresario de sí mismo. La delineación foucaultiana de las técnicas neoliberales demarcadas para modificar al trabajador en un capital humano se consolida con el ensamble de dicho trabajador a la noción de ocuparse de sí mismo como formación, crecimiento, desarrollo y acumulación, lo que implica tanto la mejora, como la valoración de sí en cuanto capital. Esto contempla una doble vía de atención al implicar elementos importantes como engañosos, dado que:

[...] ya no se concibe al trabajador como un simple factor de producción y nada más; propiamente hablando, ya no es una fuerza de trabajo, sino un capital-competencia, una máquina-competencias, que va de 
la mano de un estilo de vida, un modelo de vida, una postura moral empresarial que determina una forma de relación del individuo consigo mismo, con el tiempo, con su entorno, con el futuro, con el grupo, con la familia. (Lazzarato, 2013b, p. 114)

Desde este marco, Foucault (2007) sugiere que el Gobierno neoliberal opera sobre la misma sociedad tanto en su trama, como en su espesor, y contempla todos los procesos de corte social e incluso se hace cargo de ellos, para albergar y constituir la competencia y la empresa, y asimismo un matiz decisivo de la deuda y su economía.

Por otro lado, con los neoliberales contemporáneos la desproletarización da un acelerado salto en el interior de sus discursos (todos propietarios, todos empresarios), pero en la acción misma se desvirtúa el marco de estos discursos, especialmente en lo relacionado con la reducción salarial y los recortes presupuestarios del Estado benefactor. La economía de la deuda trae consigo una precarización no solo económica, sino también existencial, que se articula con la noción de una antigua realidad: la proletarización específica de las clases medias y los trabajadores de los nuevos oficios emergidos, en lo que antiguamente (previo a la detonación de su esfera) se llamaba new economy. Es por ello que la economía de la deuda proporciona una imagen nítida de las nuevas encarnaciones subjetivas del capital, y a las que se impulsa a moldearse al conjunto de la población. $\mathrm{Al}$ respecto:

Si la acción neoliberal recae a la vez e indistintamente sobre la economía y la subjetividad, sobre el trabajo y el trabajo sobre sí mismo, reduce este último a una exhortación a ser uno o su propio patrón, en el sentido de "hacerse cargo" de los costos y los riesgos que la empresa y el Estado externalizan en la sociedad. La promesa de lo que "trabajo sobre sí mismo" debía aportar al "trabajo" en términos de emancipación (goce, realización, reconocimiento, experimentación de formas de vida, movilidad, etc.) se ha invertido, para transformarse en el imperativo de hacer propios los riesgos y los costos que ni las empresas ni el Estado quieran asumir. (Lazzarato, 2013b, p. 108)

No obstante, al congelar los salarios y descender ampliamente las erogaciones sociales, las políticas neoliberales contemporáneas configuran y producen capital humano, un empresario de sí mismo en el marco del endeudamiento pronunciado de un modo $\mathrm{u}$ otro precario y en un rango más o menos elevado de pobreza. Ya se advierte que para una fracción importante de la población, la idea de ser empresario de sí mismo se limita a la gestión según parámetros de empresa, competencia, empleabilidad, reducción de los servicios sociales, deudas y desnivel de los salarios e ingresos.

Se exige de la población menos favorecida en términos económicos una capacidad gerencial para administrar el conjunto de asistencias y pequeños empleos, lo que implica en el sujeto la ausencia y necesidad de crear pequeña empresa de manera individual para ser empresario de sí mismo, pues es necesario configurar comportamientos que adoptan dicha lógica en actitudes, maneras de pensar, comportamientos y modos de relacionarse con los otros y con el mundo:

\footnotetext{
A partir de la crisis financiera causada por

el estallido de la burbuja del Internet, el capitalismo abandonó sus relatos épicos constituidos en torno a la libertad, la inno-
} 
vación y la creatividad del empresario, de la sociedad del conocimiento, etc. '' La población debe limitarse a tomar a su riesgo todo lo que las finanzas, las empresas y el Estado benefactor externalizan en la sociedad, iY punto! (Lazzarato, 2013a, p. 109)

Sin embargo, en este marco, en cambio de la libertad y la autonomía que la actividad empresarial debería haber aportado al trabajo, esta actividad demostró en realidad una profunda dependencia, no solo a las empresas, las finanzas o el Estado benefactor, sino también al sujeto mismo, que afirma: ipor fin soy mi propio jefe!, una demarcación de autoempresario.

\section{Pedagogía de la deuda en la educación}

\author{
"[...] el marco institucional contri- \\ buye a formar y educar al perso- \\ nal administrativo de la máquina \\ imperial, al 'entrenamiento' de \\ una nueva elite imperial". (Hardt \\ y Negri, 2002, p. 42)
}

Los organismos "imperiales", como las grandes potencias financieras multinacionales y transnacionales, los organismos comerciales (el Fondo Monetario Internacional (FMI), el Banco Mundial, el General Agreement on Tariffs and Trade (GATT, traducido como Acuerdo General sobre Aranceles Aduaneros y Comercio), entre otros) y las enormes empresas transnacionales construyen el tejido conectivo principal del mundo biopolítico en diversos marcos importantes, pues el capital siempre se ha organizado y proyectado hacia la extensión de toda la esfera global. Sin embargo, solo en la segunda mitad del siglo XX, las grandes empresas industriales y financieras, transancionales y multinacionales ger- minan realmente en la estructuración biopolítica de los territorios globales. En palabras de Hardt y Negri (2002):

\section{[...] las empresas de corte imperial como lo} son los organismos financieros, multinacionales y de comercio meramente se introducen para ocupar el espacio que había dejado libre los diversos sistemas colonialistas nacionales e imperialistas en etapas anteriores del desarrollo capitalista, desde el imperialismo europeo del siglo XIX hasta la fase fordista del desarrollo del siglo XX. (p. 42)

Las actividades y dinámicas de las grandes entidades $u$ organismos ya no se definen bajo la virtud de la coacción de un dominio netamente abstracto, ni como una organización de ingenuo asalto, ni de intercambio desigual, sino que devienen como entidades que estructuran y se articulan directamente desde los territorios y las poblaciones. Tienden a modificar los Estados-nación y a constituirlos como meros instrumentos que registran los movimientos o flujos de mercancías, poblaciones y monedas que colocan en circulación. Estas empresas u organismos imperiales transnacionales disponen y distribuyen directamente la fuerza laboral en los múltiples mercados, y asignan en términos funcionales los recursos y el orden bajo un linaje jerárquico de los diversos sectores de la producción mundial. El complejo dispositivo u aparato que selecciona las inversiones y dirige las maniobras financieras y monetarias determina la nueva radiografía del mercado mundial. En otras palabras, la nueva estructuración biopolítica del mundo:

El panorama más complejo de este mundo se presenta en la perspectiva monetaria. Desde este punto de vista puede ver- 
se un horizonte de valores y una máquina de distribución, un mecanismo de acumulación y un medio de circulación, un poder y un lenguaje. No hay nada, ninguna "vida al desnudo", ningún punto de vista externo, que pueda plantearse fuera de este campo atravesado por el dinero, nada escapa al dinero. La producción y la reproducción visten ropas monetarias: en realidad, en el escenario global, toda figura biopolítica lleva puesto un atavío monetario. “iAcumulad, acumulad! ¡Ésa en la voz de Moisés y sus profetas!" [...] Los grandes poderes industriales y financieros producen, no sólo mercancías, sino también subjetividades. Producen subjetividades que a su vez son agentes dentro de contexto político: producen necesidades, relaciones sociales, cuerpos y mentes, lo que equivale a decir que producen productores. En la esfera biopolítica la vida debe trabajar para la producción y la producción, para la vida. Es una gran colmena en la que la abeja vigila continuamente la producción y la reproducción. Cuanto más profundamente avanza el análisis, tanto mayor es el número de articulaciones intervinculantes de relaciones interactivas que encuentra. (Hardt y Negri, 2002, p.44)

La exposición de este preámbulo sirve de subestructura para la proyección de dichas dinámicas, formas, dispositivos e instrumentos que confiere el tema de la financiación, sus organismos imperiales de orden global y cómo desde estas instituciones y sus respectivas configuraciones permea un contexto puntual, como lo es la educación superior y su conexo con aquellos dispositivos de mercantilización, propios de un sistema capitalista imbricado en marcas biopolíticas para la producción de una subjetividad específica. A continuación, se presenta una exposición puntual acerca de aquellos hilos coercitivos, de producción somática y de actuación, así como otros elementos propios de la superestructura dentro de la estructura material fundamental, no solo en definición de términos económicos, sino también culturales, corporales y subjetivos. En este marco, es valioso comprender que:

Las reflexiones que se han hecho a lo largo de la historia acerca de la relación entre educación y sociedad han partido siempre de un supuesto fundamental: se educa a los miembros de la misma para que puedan llevar a cabo ciertas conductas, de las cuales depende su mantenimiento o su progreso. Se asume entonces que las acciones de los componentes sociales son susceptibles de ser creadas, dirigidas o corregidas, con el propósito de llevar a cabo un cierto proyecto de sociedad. Desde la posición griega de la relación necesaria entre ciudadanía y Paideia hasta la profesionalización universitaria, pasando por las ideas ilustradas sobre el sentido de la educación y por sus múltiples críticas; educación y sociedad se encuentran en la construcción de aparatos sociales diseñados para promover y controlar las acciones de sus diversos componentes. (Martínez, 2014 p. 174)

Es significativa la importancia que tienen los préstamos universitarios como un mecanismo facilitador para aquellos que quieren acceder a una formación profesional, entendida esta como un puente que se instaura en la representación de progreso y desarrollo de la vida a futuro. Así, acceder a la participación de mecanismo de crédito y préstamo es la nueva forma de financiación de las 
carreras. En efecto, al realizar una observación detenida de la educación superior, podemos encontrar que esta se ha convertido en un beneficio para quienes tienen condiciones económicas privilegiadas; por el contrario, otros jóvenes y sus familias deben refugiarse en adquirir grandes deudas, a fin de tener un "mejor futuro". Este panorama enseña cómo germina un asentamiento a la desigualdad y el desequilibrio en el acceso a la educación superior, donde se posiciona una educación que dejó de ser un beneficio social para convertirse en un lujo particular. En consecuencia, la deuda estudiantil se ha impuesto, no en mucho tiempo, como el nuevo paradigma de la vida de los jóvenes y sus familias.

Actualmente el paradigma de financiación universitaria ya no es de tutela pública, siendo compensada y subvencionada por el Estado, sino que es un servicio privatizado, lo que significa que los ciudadanos tienen que asumir una parte fundamental del mismo [...] "Estado de post-bienestar universitario" [...] Los préstamos funcionan según la lógica del Estado de post-bienestar en la medida en que reconfiguran la financiación universitaria no como un derecho o una beca, sino como un auto-pago -fomentando "la responsabilidad personal"-; y no como un servicio estatal, sino como un servicio privatizado, administrado por súper-bancos. (Williams, 2010, pp.74 y 75)

Williams (2010) rescata, además, la siguiente reflexión:

Atrás quedan los días en los que la universidad estatal era considerada un derecho al que todos podían tener acceso, al igual que la educación secundaria. Ahora la educación superior, como la mayor parte de los servicios sociales, se encuentra ampliamente privatizada y los préstamos son el medio a través del cual los individuos acceden a ella. (p. 71)

Guaranteed Student Loan, como programa de préstamos garantizado para estudiantes, inició en 1965, como parte de los programas de la sucursal de Lyndon B. Johnson's Great, donde su misión se concentra descrito en "[...] proporcionar un sustento a los estudiantes menos pudientes y a los que trabajaban. Los primeros doce años, las cantidades prestadas fueron relativamente pequeñas, en gran parte porque la educación universitaria era relativamente asequible, especialmente en las universidades públicas" (Williamns, 2010, p.72). En la actualidad, los créditos universitarios se han configurado como la principal fuente de financiación de los estudios profesionales, siendo el endeudamiento la nueva realidad en la vida de los jóvenes. Frente a ello, es fundamental preguntar qué es el crédito o la deuda en su representación más desnuda, si entendemos esta última como una promesa de pago. Cabe problematizar, en palabras de Lazzarato (2013b):

¿Qué es un activo financiero, una acción o una obligación? La promesa de un valor futuro. "Promesa", "valor", y "futuro" son así las palabras claves de la segunda disertación nietzscheana. Para Nietzsche, la relación "más antigua y primitiva que existe entre las personas" es la relación entre acreedor-deudor. En ella, la persona se mide por primera vez con la persona. Por consiguiente, la tarea de una comunidad o una sociedad ha sido, ante todo, la de generar un hombre capaz de prometer, un hombre en condiciones de cancelar su deuda. Fabricar un hombre capaz de mantener 
una promesa significa construirle una memoria, dotarlo de una interioridad, de una conciencia que pueda oponerse al olvido. La memoria, la subjetividad y la conciencia comienzan a fabricarse en la esfera de las obligaciones de la deuda. (pp. 45 y 46)

En este orden de ideas, se perpetúa una lógica profunda de financiación que conecta a los sistemas de educación superior con otros campos u organismos de la sociedad, lo que demarca la movilidad y el aumento de préstamos, con aras de solventar pagos correspondientes a las elevadas matrículas universitarias. Esta cuestión comprende un problema de amplitud, que no solo vincula a los estudiantes, sino también a todos los miembros del núcleo familiar, lo cual moviliza dinámicas tanto de las familias como de los propios jóvenes, al ser ellas las que respaldan y se comprometen con la adquisición de créditos, pues respaldan esos préstamos con la hipoteca de sus bienes; este hecho se convierte en uno de los principales motivos del endeudamiento colectivo. Insistimos en lo siguiente:

La pedagogía de la deuda ha sido la forma de nombrar la deuda constante en la cual se registran los jóvenes con la finalidad de obtener el servicio de educación superior, que ha dejado de ser un derecho y resulta cada vez más privatizado. Esta deuda llega a convertirse en un "paradigma" y resulta decisiva, pues su monto ha aumentado considerablemente para cuando el joven se gradúa. (Martínez, 2014, p.103)

Una pedagogía de la deuda implica no solo la formación y el adiestramiento de los sujetos, de tal manera que se asegure y garantice el pago de los créditos obtenidos que en la red demanda un endeudamiento, sino que implica además una subjetivación, un trabajo so- bre sí mismo, como si fuese una "tortura" de sí mismo. Este trabajo es la producción del sujeto individual, capaz de responder frente a su acreedor; en síntesis, en deuda con él. En este sentido y bajo el marco de este estudio, la universidad como su contexto específico, cabe traer a colación algunas manifestaciones que los y las estudiantes solían decir:

[...] "estoy labrando mi camino a través de la universidad". Ahora sería imposible hacerlo si no tienes poderes sobrehumanos. De acuerdo con las estadísticas, durante los años sesenta, un estudiante podía trabajar 15 horas semanales por el sueldo mínimo durante el período lectivo y 40 horas en verano para pagarse la universidad pública. Para una universidad privada o un Ivy tendría que trabajar cerca de 20 horas semanales. Actualmente, necesitaría trabajar 52 horas semanales durante todo el año si estudia en una universidad pública, 136 horas semanales si frecuenta un Ivy. (Williams, 2010, p. 73)

En esta perspectiva,

[...] toda la innovación financiera no tiene más que una finalidad: objetivar el futuro para poder disponer de él de antemano. Esta objetivación es de naturaleza muy distinta de la del tiempo del trabajo; objetivar el tiempo, diposner de él de atemano, significa que toda posibilidad de elección y decisión que encierre el futuro queda subordinada a la reproducción de las relaciones de poder capitalista. De tal modo, la deuda no sólo se apropia del empleo actual de los asalariados y del conjunto de la población, sino que tiene también un derecho preferencial sobre el tiempo no cronológico, el 
futuro de cada quien y el porvenir de toda la sociedad. (Lazzarato, 2013a, p. 54)

Desde este marco, la educación superior pasa de ser un bien social a un bien individual. En la época de la posguerra, el objetivo social se concentraba en producir científicos, ingenieros y humanistas que contribuyeran a la sociedad misma; actualmente, la educación pasa a ser un puente en términos de bien para que los sujetos adquieran mejores oportunidades laborales y, por ende, mayores ingresos, siendo entonces los créditos una inversión personal en el potencial individual. De esta manera,

El aspecto fundamental que se destaca es el paso de la educación superior como bien social a ser un bien individual. En ese giro, los individuos "atomizados" ingresan a la educación superior en busca de un mejor trabajo o mayores ingresos; es decir, la lógica del mercado funciona como un plus para el potencial económico. Los préstamos son una inversión personal, no social; por ello, su horizonte se proyecta hacia la potencia del individuo, y no de la sociedad en su totalidad. (Martínez, 2014, p. 104)

La globalización y la modernización dan luz a una universidad vista como universidad-negocio, donde priman y se cotejan términos empleados en las empresas, tales como calidad y profesionalidad. Así, la universidad se convierte en una empresa comercial capaz de sostenerse gracias a los beneficios y demandas del mercado; en una institución que se transforma ella misma en agencia de franquicias, en la que la compañía privada asegura contratos (comerciales) de investigación y procura clientes para su financiación. La universidad accede al desarrollo de estos proyectos, que responden a las necesidades de actores económicos capaces de garantizar un retorno económico. Esto desdibuja la idea de universidad como escenario de investigación pública, que construye un saber diversificado, plural y crítico, para la satisfacción de las necesidades o demandas del mercado; es una práctica neoliberal donde las nociones se transforman para la constitución de sujetos como capital humano. Esto significa que:

[...] los procesos económicos devienen espacios para la producción de la subjetividad "producción de productores" y no se organiza ya solamente desde dispositivo de corte disciplinario, sino desde una captura y un diseño biopolítico de la subjetividad, en el sentido del término. La producción de esta subjetividad desde las técnicas gubernamentales del liberalismo supone, entonces, la emergencia de una forma vital productiva que no solo está regulada por las leyes del mercado, sino que ahora convierte todo un modelo social capturado por la "empresa" en el cual la deuda es una inversión en la propia subjetividad e términos de ser o devenir empleable. Son estas características de la cuestión del "sujeto competente y competitivo" y de la educación como una herramienta constante en la producción y el mantenimiento de la subjetividad. (Martínez, 2014, p. 107)

Desde esta perspectiva, la educación, y en especial la universitaria, se localiza en el núcleo de la problemática, al encontrarse en la frontera entre la vida para la producción profesional y la preparación científica y técnica para esta misma, en respuesta a una sociedad con linajes capitalistas del mercado. 


\section{Referencias}

Deleuze, G (1968). Nietzsche y la filosofía. Barcelona: Anagrama.

Deleuze, G y Guattari, F (1972). El anti-Edipo: capitalismo y esquizofrenia. Barcelona: Paidós.

Foucault, F (1999). Verdad y poder. En Obras esenciales II: Estrategias de poder (pp. 5493). Barcelona: Paidós.

Foucault, M. (2007). Nacimiento de la biopolítica. Buenos Aires: Fondo de Cultura Económica.

Hardt, M y Negri, A. (2002). Imperio. Buenos Aieres: Paidós.
Lazzarato, M. (2013a). Gobernar a través de la deuda. Tecnologías de poder del capital neoliberal. Amorrortu.

Lazzarato, M. (2013b). La fábrica del hombre endeudado. Ensayo sobre la condición neoliberal. Buenos Aires: Amorrortu.

Martínez, J. (2014). Subjetividad, biopolítica y educación: una lectura desde el dispositivo. Bogotá: Ediciones Unisalle.

Williams, J. (2010). La pedagogía de la deuda. En Edu-Factory y Unversidad Nómada (Comps.), La universidad en conflicto. Capturas y fugas en el mercado global del saber (p. 71-82). Madrid: Traficantes de Sueños. 